\title{
OLHANDO A MONTANHA: PARÂMETROS E PROCESSOS DA ECOLOGIA EDUCACIONAL INDÍGENA
}

Gregory Cajete*

Tradução: Charles Bicalho**

RESUMO: Tradução do prefácio do livro Look to the mountain - an ecology of indigenous education, de autoria do educador indígena Gregory Cajete, do pueblo de Santa Clara, no estado do Novo México, nos Estados Unidos. Em seu prefácio, Cajete traça os parâmetros e processos que subjazem à sua proposta, que destaca a importância de uma abordagem inclusiva da natureza num processo que tem como base uma "ecologia da educação indígena", e sugere a investigação de uma alternativa educacional contemporânea para os povos indígenas fundamentada culturalmente na concepção dos povos tradicionais. Segundo o autor, seu livro se configura enquanto uma tradução de princípios de uma educação voltada a um quadro contemporâneo do pensamento. Seu projeto de educação como comunicação intercultural se apresenta como uma metáfora alternativa diferente da que se pratica hegemonicamente na América. Tradicionalmente os índios veem a vida através de uma metáfora cultural diferente. É esta metáfora cultural diferente que emoldura a exploração da filosofia educacional indígena apresentada no livro.

PALAVRAS-CHAVE: ecologia; educação; indígena; ameríndio
** charlesbicalho@gmail.com

Pós-Doutor em Mídia e Estudos Literários. Escola de Design da Universidade do Estado de Minas Gerais.

ABSTRACT: Translation of the preface of the book Look To The Mountain - An Ecology Of Indigenous Education, by the indian educator Gregory Cajete, from Santa Clara pueblo, in New Mexico state, United States. In his preface, Cajete outlines the parameters and processes that underlie its proposal, which highlights the importance of an inclusive approach to nature in a process that is based on an "ecology of indigenous education," and suggests the investigation of a contemporary educational alternative to indigenous peoples culturally based on the realm of American Indian people. According to the author, his book is configured as a translation contemporary frame of thought. His educational project as intercultural communication is presented as an alternative metapho other than that practiced in hegemonic America. Traditionally Indians see life through a different cultural metaphor. It is this different cultural metaphor that frames the exploitation of indigenous educational philosophy presented in the book.

KEYWORDS: ecology; education; indigenous; American Indian
Gregory Cajete é indígena do pueblo de Santa Clara, localizado no estado do Novo México, Estados Unidos. É professor nániversidade do Novo É director do departamquerque. E director do departamento de Native American Studies e Professor Associado na Division of Language, Literacy and Socio Education da UNM É Education da UNM. É autor dos livros Look to the Mountain: An Ecology of tndigenous Education (Kivaki Press, 1994), Ignite Science Education Curriculum Model (Kivaki Press, 1999); Spirit of the Game: Indigenous Spirit of the Game: Indigenous
Wellsprings (Kivaki Press, 2005); A People's Ecology: Explorations in Sustainable Living (Clearlight Publishers, 1999) e Native Science: Natural Laws of Interdependence (Clearligh Publishers, 2000) 
As perspectivas, orientações, ideias, modelos e interpretações apresentadas aqui são uma sintese pessoal baseada em meu próprio processo criativo como um educador indígena. Este livro é uma reflexão de meu entendimento particular das metáforas compartilhadas pelos índios americanos relativas à educação tribal. É uma exploração inclusiva da natureza da educação indígena. Reflete sobre as possibilidades criativas inerentes à introdução de uma moldura indígena de referência como uma importante consideração no desenvolvimento de uma filosofia contemporânea da educação indígena americana. Como um todo, este trabalho esboça elementos chave da orientação para o ensino e aprendizagem tribal do índio americano. Representa minha percepção de "uma ecologia da educação indígena".

Este livro é também uma carta aberta para educadores indígenas, para aqueles envolvidos com as questões da educação indígena, e outros povos indígenas que desejam considerar as possibilidades culturais alternativas da educação Minha abordagem tem sido aquela de um professor explorando as dimensões do ensino e do aprendizado indígena de modo criativo. O relato dessa jornada, seu currículo, se tornou este livro. Professores criam currículos (ciclos de ensino e aprendizagem) através da criação constante de modelos que são aplicados às situações reais de ensino. Idealmente, os professores constantemente ajustam seus modelos para se adequarem a seus alunos e às diferentes realidades do processo educativo. Através deste constante e criativo ajuste, professores e estudantes se engajam numa relação simbiótica e geram laços de experiência em torno do que se aprende. Deste modo, professores estão sempre criando suas histórias, inclusive enquanto eles as estão contando.

Este trabalho explora uma alternativa culturalmente fundamentada de pensar e possibilitar uma educação contemporânea dos povos indígenas. É uma tradução de princípios fundacionais de educação tribal para um quadro contemporâneo de pensamento e descrição. Advoga o desenvolvimento de um processo educativo contemporâneo e culturalmente embasado, fundado em valores, orientações e princípios tribais tradicionais, enquanto simultaneamente se utiliza dos mais apropriados conceitos, tecnologias e conteúdo da moderna educação.

Extratos do pensamento e da tradição indígena usados neste trabalho representam aspectos essenciais da ecologia da educação indígena. Cada extrato é apresentado com meu mais profundo respeito, honrando a riqueza das entidades indígenas. $\mathrm{O}$ conteúdo representa uma pequena porção do que está disponível na vasta amostragem de investigações relacionadas às culturas ameríndias. As culturas ameríndias estão entre as mais estudadas no mundo. $\mathrm{O}$ acesso a este vasto oceano de conteúdo, facilitado pelos educadores 
indígenas e estudiosos, é um passo essencial na criação de uma epistemologia contemporânea da educação indígena. O acesso e a revitalização das bases indígenas da educação deve ocorrer, não só nas salas de aula contemporâneas, mas também nas comunidades indígenas. Todos os povos indígenas, jovens e velhos, profissionais e amadores, deveriam considerar a si mesmos como participantes de um processo de avanço em direção à educação de base indígena. Depende de cada comunidade indígena, estejam elas vivendo em ambiente urbano ou em reservas, decidir como suas necessidades relativas à manutenção ou revitalização cultural podem ser direcionadas através da educação; e depende também de cada comunidade indígena decidir o que é apropriado para ser introduzido através do veículo da educação moderna e o que é apropriado para ser transmitido com mecanismos tradicionais.

A educação moderna e a educação tradicional não podem mais se dar ao luxo de permanecerem histórica e contextualmente separadas. Cada comunidade deve integrar o aprendizado que ocorre através da educação moderna com as bases culturais do conhecimento e os valores essenciais para perpetuar seu modo de vida. Uma integração equilibrada deve ser criada. Com o tempo, a ênfase no currículo de orientação ocidental vai corroer os modos indígenas de viver. Educadores indígenas e líderes tribais devem entender que a aplicação da educação ocidental sem um exame crítico pode condicionar as pessoas para longe de suas raízes culturais. A educação moderna provê ferramentas essenciais para a sobrevivência dos povos e comunidades indígenas, mas essa educação deve se dar no contexto de uma totalidade cultural maior. Em apoio à preservação cultural, educadores indígenas e líderes tribais precisam também advogar pela educação baseada na cultura para alcançar os objetivos fundacionais da auto determinação, da auto governança e da soberania tribal. A educação indígena se oferece como um veículo altamente criativo para se pensar sobre a perpetuação das culturas ameríndias enquanto elas adentram o século XXI.

A investigação sobre a educação indígena apresentada neste livro inclui a expressão dos universais contidos no processo educacional sob a perspectiva do pensamento tradicional ameríndio. Suas fundações jazem na aplicabilidade de suas perspectivas para todo o processo de ensino e aprendizado - não só o ameríndio. Os universais explorados aqui devem ser vistos como arquétipos do aprendizado humano e como parte da psique indígena de todos os povos e tradições culturais. Todas as fontes relevantes de pensamento, pesquisa e filosofia educacional - de várias fontes culturais - foram consideradas, para iluminar as possibilidades de uma educação contemporânea que espelhe o pensamento indígena 
e sua orientação primária de relacionamento com o mundo natural. Sendo assim, a hipótese deste trabalho pode ser aplicada aos nativos do Havaí, aos aborígenes da Austrália, aos bosquímanos da África, bem como a outros povos in dígenas que buscam revitalizar suas histórias primordiais através da educação.

\section{O DILEMA CONTEMPORÂNEO DA EDUCAÇÃO \\ AMERÍNDIA}

Um problema penetrante que afeta a visão contemporânea da educação ameríndia é que sua definição e evolução tem sido sempre dependente da política. Muito do que caracteriza a política educacional indígena não é resultado de pressupostas pesquisas sobre as orientações filosóficas ameríndias, mas sim resultado de Atos do Congresso, ou seja, a história da interpretação pelas cortes dos tratados de direito, e a histórica relação entre índios e brancos específica de cada grupo tribal ou região geográfica. Historicamente, as visões que guiam a evolução da moderna educação indígena não têm sido firmadas sobre a presunção que de são representativas das perspectivas indígenas. Apesar de tais orientações políticas, processos educacionais tradicionais continuaram no contexto de muitas famílias e comunidades indígenas. Se por um lado tem havido progresso nos últimos vinte anos, por outro lado a integração dessas duas abordagens na educação foi praticamente inexistente.
A base da educação americana contemporânea é a transferência de habilidades e conteúdos acadêmicos que preparam o estudante para competir na infraestrutura da sociedade americana enquanto definida pela prevalência da ordem política, social e econômica. A teoria educacional americana é geralmente desprovida de conteúdo ético ou moral relativos aos meios usados para alcançar seus fins. O currículo ideal abraçado pela educação americana termina por ser significativamente diferente do currículo prático internalizado pelos estudantes. A sociedade americana que tantos estudantes indígenas experimentam é forjada em contradições, preconceito, hipocrisia, narcisismo e predisposições antiéticas em todos os níveis, incluindo as escolas. Continua a haver conflitos educacionais, frustrações e níveis variados de alienação experimentados por muitos povos indígenas em rota de colisão com a educação hegemônica.

Um obstáculo fundamental para a comunicação intercultural gira em torno de diferenças significantes em termos de orientações culturais e do fato de os povos indígenas terem sido forçados a se adaptar a um processo educacional de cuja criação não participaram. Tradicionalmente, os índios veem a vida através de uma metáfora cultural diferente daquela da América hegemônica. É esta metáfora cultural diferente que emoldura a exploração da filosofia educacional indígena apresentada neste livro.

EM TESE

BELO HORIZONTE

v. 22

N. 2

MAIO-AGO. 2016

CAJETE; BICALHO. Olhando a montanha: parâmetros e processos [...]

. 148-156

Tradução e Ediç̧ão 
A educação indígena tradicional representa uma anomalia para a teoria e a metodologia prevalentemente objetivistas da educação ocidental. A aplicação do objetivismo implica em haver uma única maneira correta de entender as dinâmicas da educação indígena, uma única metodologia correta e uma única política correta para a educação indígena. E esta única maneira é a maneira da América hegemônica. A men talidade objetivista, quando aplicada ao campo da educação indígena, exclui importantes considerações sobre a realidade relacional dos povos indígenas, as variações em contextos tribais e sociais, e os processos de percepção e entendimento que caracterizam e formam suas expressões.

A pesquisa objetivista contribuiu enormemente para o conhecimento, mas tem limitações substanciais em relação à realidade multidimensional, holística e relacional da educação dos povos indígenas. São os elementos afetivos - a experiência subjetiva e a observação, os relacionamentos comuns, as dimensões mística e artística, o ritual e a cerimônia, a ecologia sagrada, as orientações espiritual e psicológica - que caracterizam e enformam a educação indígena desde tempos imemoriais. Tais dimensões e seus significados inerentes não são prontamente quantificáveis, observáveis ou facilmente verbalizados, e, como resultado, têm recebido pouco crédito nas abordagens corriqueiras à educação e pesquisa. Contudo, são esses aspectos da orientação indígena que dão forma a um contexto profundo de aprendizado através da exploração das relações multidimensionais entre humanos e seus mundos internos e externos.

Para os educadores indígenas, uma chave para lidar com o conflito entre as orientações objetivista e relacional, o viés cultural, e as diferenças culturais de percepção, está na comunicação aberta e no diálogo criativo, que desafiam a infraestrutura tácita de ideias que guiam a educação indígena hoje em dia.

Educação é essencialmente uma atividade social comunal. A pesquisa educacional que gera o conhecimento criativamente mais produtivo envolve a comunicação no contexto de toda a comunidade educacional, e não apenas em relação às autoridades reconhecidas pelos interesses educacionais hegemônicos. Educação é um processo comunicacional e desempenha um papel essencial em todo ato de percepção cognitiva. Deve haver um fluxo de comunicação relativamente ao processo educacional entre todos os educadores como resultado de um diálogo interno individual, de publicação e de discussão de ideias.

As ideias baseadas na tácita infraestrutura da educação americana hegemônica têm sido adotadas de uma forma relativamente pouco crítica por muitos educadores. Esta situação, no que se refere à educação indígena, limita a criatividade 
da percepção. Precisamos de um desempenho livre do pensamento e de uma ampliação de campo. Somente entendendo que há uma tácita infraestrutura, e então questionando-a, é que um alto nível de pensamento criativo pode se tornar possível em relação ao potencial da filosofia educacional indígena. Somente após o entendimento de que as percepções ameríndias da educação foram tradicionalmente formadas por uma metáfora diferente do ensinar e do aprender é que se desenvolverá um conhecimento mais produtivo no campo da educação indígena contemporânea.

Tais metáforas tradicionais da educação derivam seus significados dos contextos culturais únicos e das interações com os ambientes naturais. Por outro lado, as experiências coletivas dos povos indígenas e suas adaptações culturais culminaram num conjunto de metáforas relacionadas à natureza da educação e sua ecologia essencial.

Esta investigação sobre a educação indígena tenta desenvolver uma compreensão comum de metáforas e ideias que são compartilhadas especificamente pelas culturas indígenas, e que ainda reflita a natureza do aprendizado humano como um todo. Sistemas tradicionais de educação indígena representam modos de aprendizagem e realização pelo viés de uma filosofia centrada na natureza. Estão entre as mais antigas expressões da educação "ambiental" no mundo. Tomados em sua totalidade, tais sistemas representam um processo de educação ambiental com significado profundo para a educação moderna, enquanto esta enfrenta o desafio de viver no século XXI. Este processo tem o potencial de criar um entendimento mais profundo de nossa função coletiva enquanto cuidadores de um mundo cujo equilíbrio nós ameaçamos.

Este livro é essencialmente uma continuação de minha dissertação Ciência: uma perspectiva nativoamericana (um modelo curricular de educaşão científica baseado na cultura) produzida sob os auspícios do New Philosophy Program do Internacional College. As carências percebidas que motivaram minha dissertação continuam a formar o ímpeto para este trabalho. Tais carências podem ser resumidas como se segue:

1. A necessidade de uma perspectiva contemporânea para a educação ameríndia que seria derivada e formada principalmente pelos pensamentos, orientações e filosofias culturais dos próprios povos indígenas. A articulação e a execução dessa necessidade são, eu acredito, estágios essenciais na autodeterminação educacional indígena.

2. A necessidade de investigar abordagens educacionais alternativas que direta e satisfatoriamente encaminhem as demandas das populações indígenas durante o período de crise educacional e ecológica vivido atualmente. É essencial alargar o campo e acolher as possibilidades de novas 
abordagens numa busca criativa por processos educacionais completos e viáveis.

3. A necessidade de integrar, sintetizar, organizar e focalizar o material acumulado de uma ampla gama de disciplinas sobre as culturas e a educação in dígenas em direção ao desenvolvimento de uma filosofia contemporânea voltada para a educação ameríndia que seja realmente de inspiração indígena e de base ecológica.

A educação ameríndia contemporânea tem focado em índios aprendendo as habilidades necessárias à produtividade - ou ao menos à sobrevivência - na sociedade americana pós-industrial. Os ameríndios têm sido encorajados a ser consumidores de acordo com a tradição do sonho americano e todas as suas implicações. Os índios têm sido encorajados a usar a educação moderna para progredir através da participação no sistema e pela busca das recompensas que o sucesso supostamente oferece. Ainda que muitos tenham sido bem sucedidos ao abraçar a educação ocidental, os povos indígenas devem questionar os efeitos da educação moderna sobre a sua viabilidade coletiva cultural, psicológica e ecológica. O que tem sido ganho e o que tem sido perdido por participar de um sistema de educação que não privilegia exclusivamente as perspectivas indígenas? Quão longe podemos ir ao nos adaptar a tal sistema, antes que o sistema literalmente eduque os povos indígenas fora de sua existência cultural. Os povos indígenas chegaram ao limite do que eles podem fazer com as orientações da educação hegemônica? Como eles podem revisar e refazer a ecologia da educação que enforma e mantém as sociedades tribais?

Ironicamente, muitos pensadores ocidentais criativos têm adotado pontos de vista essenciais da educação ambienta indígena e estão vigorosamente se apropriando de conceitos indígenas para dar suporte ao desenvolvimento de seus modelos alternativos. Por exemplo: o historiador e filósofo cultural Thomas Berry, que propõe um novo contexto para a educação que essencialmente reinventa as regras e contextos inerentes à educação indígena:

O educador primordial, assim como o legislador primordial e o curador primordial seriam o próprio mundo natural. A comunidade integral planetária seria uma comunidade auto-educada no contexto de um universo auto-educativo. A educação em nível humano seria a sensibilização consciente dos seres humanos a respeito das comunicações profundas realizadas pelo universo para conosco, através do sol, da lua, das estrelas, das nuvens, da chuva, dos contornos da terra e de todas as suas formas de vida. Toda música e poesia do universo fluiria para dentro do estudante; a presença revelatória da divindade, bem como a compreensão das estruturas arquiteturais dos continentes e as habilidades de engenharia por meio das quais o grande ciclo hidrológico opera a moderação da

EM TESE

BELO HORIZONTE

v. 22

N. 2

MAIO-AGO. 2016

CAJETE; BICALHO. Olhando a montanha: parâmetros e processos [...]

P. $148-156$

Tradução e Edição 
temperatura na terra, provendo habitat para a vida aquática e alimentando a multidão de seres vivos, tudo isso seria natural ao processo educacional. A terra seria por sua vez nosso professor primordial de ciências, especialmente as biológicas, de indústria e de comércio. Ela nos ensinaria um sistema no qual criaríamos o mínimo de entropia, um sistema no qual não haveria lixo inútil e descartável.

Somente neste sistema integral está assegurada a viabilidade humana.

Os comentários de Berry fazem coro com explicações coincidentes aos processos educacionais indígenas de sociedades tribais. É no contexto iluminador desta visão que esta história deve se desenrolar tanto para índios quanto para não índios. Se nosso futuro coletivo é para ser harmonioso e totalizador, ou se estamos mesmo habilitados a um futuro viável a ser transmitido aos netos de nossos netos, é imperativo que se vislumbrem e que se implementem novas formas de educação ecológica e sustentável. A escolha é nossa, ainda que paradoxalmente possamos não ter escolha.

\section{CONTANDO UMA HISTÓRIA}

Este livro é sobre a visão e a exploração criativa de escolhas que a educação ameríndia oferece quando nós coletivamente "olhamos para a montanha" procurando por uma ecologia da educação que possa nos dar sustentação no século XXI. Este livro explora uma visão da educação que se revela enquanto seguimos uma história muito especial. Seu enredo é sobre os modos únicos de ensino e aprendizagem ameríndia. É uma reverência ao processo de busca pela vida que os povos ameríndios representam e refletem através de suas conexões especiais com a natureza, com a família, com a comunidade, e com a ecologia espiritual. É uma reverência às conexões e ao lugar que o ensino e a aprendizagem tradicionais têm na vida ameríndia. Este livro mapeia uma jornada através das metáforas compartilhadas e faz uma parada para reconhecer, apreciar e contemplar a educação ameríndia tradicional, suas implicações para o futuro das crianças ameríndias, e as culturas tribais que elas transmitirão ao longo do século XXI.

Nesta jornada focalizaremos um ciclo de relacionamentos que coincidem com os sete processos de orientação: a preparação, o questionamento, a busca, o fazer, o entendimento, o compartilhamento e a celebracão da sabedoria especial da educação tribal ameríndia. Relacionamento ambiental, mito, tradições visionárias, artes tradicionais, comunidade tribal e a natureza espiritualmente centrada têm tradicionalmente formado as fundações da vida ameríndia ao descobrir a face verdadeira de alguns (o caráter, o potencial, a identidade), o coração (a alma, o íntimo criativo, a verdadeira paixão), e
EM TESE
BELO HORIZONTE
v. 22
N. 2
MAIO-AGO. 2016
CAJETE; BICALHO. Olhando a montanha: parâmetros e processos [...]
P. $148-156$

Tradução e Edição 
as fundações de alguém (o trabalho verdadeiro, a vocação), enfim, tudo o que conduz à expressão de uma vida completa.

Este trabalho esboça um modo de percepção e pensamento criativo enquanto relacionado à educação. Assim como o proverbial Kokopeli, eu desejo semear sementes de pensamento e reflexão profunda relativamente à natureza da educação indígena. Desejo chamar a atenção para um modo de ver e entender um processo primordial de educação fundamentado sobre as bases da natureza humana. É um modo de educação prenhe de potencial, não apenas para a transformação do que está erroneamente nomeado como "educação indígena", mas também para suas aplicações profundas em direção à transformação da educação moderna. Devemos desenvolver a abertura e a coragem para dar um salto criativo com vistas a encontrar uma visão transformadora em nossas vidas, para o bem de nossas crianças e de nós mesmos.

Este livro expressa a experiência da vida ameríndia que acabei por conhecer. Escrevo como um educador para outros educadores. Escrevo em apoio às crianças, aos povos e às comunidades ameríndias. Escrevo para fortalecer suas forças, sua coragem, sua criatividade e as contribuições que eles virão a dar. Escrevo em favor da vida e com o entendimento de que a educação é uma arte do processo, da participação e das conexões. Aprender é um crescimento e um processo de vida; e a vida e a natureza são sempre relacionamentos em processo!

\section{REFERÊNCIA}

CAJETE, Gregory. Look to the mountain: an ecology of indigenous education. Rio Rancho, New Mexico, USA: Kivaki Press, 1994. ISBN: 1-882308-65-4 